\title{
Brand Extension as Informational Leverage
}

Jay Pil Choi, Columbia University

August 1997

Discussion Paper Series No. 9697-26 


\title{
Brand Extension as Informational Leverage
}

\author{
by
}

Jay Pil Choi*

April 1996

revised August 1997

\begin{abstract}
The marketing literature refers to the concept of brand capital and provides empirical evidence that firms with a large stock of well-established brands have an advantage in introducing new products. This paper develops a theory of brand extension as a mechanism for informational leverage in which a firm leverages off a good's reputation in one market to alleviate the problem of informational asymmetry encountered in other markets. It is shown that brand extension helps a multi-product monopolist introduce a new experience good with less price distortion. Thus, the paper provides a theoretical foundation for the concept of brand capital.
\end{abstract}

JEL Classification Numbers: L1, D4, D8, M3.

Keywords: brand extension, informational leverage, reputation, experience goods.

Correspondent:

Jay Pil Choi

Department of Economics

Columbia University

New York, NY 10027

U.S.A.

Tel.:212-854-5488

Fax.: 212-854-8059

E-mail:jpc8@columbia.edu

*I am grateful to Patrick Bolton, Charles Horioka, Ben Polak and an anonymous referee for helpful comments and encouragement. Any remaining errors are my own responsibility. This paper was revised while I was visiting the Institute of Social and Economic Research, Osaka University, Japan. I wish to express my gratitude to Tatsuo Hatta, Hajime Miyazaki, and Chikashi Moriguchi who made my visit to the Institute possible. 


\section{Introduction}

Brand extension is a marketing practice that uses an established brand name in one category to introduce products in totally different categories. This practice has been widely used by a variety of firms to introduce new experience goods and was hailed as "the single most important trend" in marketing [Ries and Trout (1981)]. ${ }^{1}$ Examples abound. Procter and Gamble, for instance, is known for its extensive use of established brand names in introducing new products, as seen in the flood of new Tide products. Lysol has built a line of products that deodorize the air, the toilet, tiles, etc. Ivory shampoo is a brand extension of Ivory soap. According to Tauber (1988), almost half of all new package goods are estimated to be brand extensions.

The prevalence of brand extension in practice attracted the attention of researchers in marketing. They explain that brand extension allows the established brand name to provide a stock of information about the new product's quality [Aaker (1990)]. Thus, brand extension makes it possible for a new product to be launched at lower cost by using informational leverage provided by an established brand name [Peckman (1971)]. This advantage of brand extension seems to be corroborated by empirical studies. Tauber (1988), for instance, finds that introducing a product via brand extension costs $\$ 50$ million on average in comparison to $\$ 150$ million on average when a product is introduced with a new name brand. Smith and Park (1990) also show that firms using brand extension spend less on advertising expenditures than firms with comparable new name products for a given level of sales. Few studies, however, analyzed formally the mechanism through which brand extension can be useful in introducing a new product. 
This paper provides a reputation model of brand extension in which a firm stakes its reputation as a bond for quality in using brand extension as a signal of quality. More specifically, I consider the experience goods market in an infinite horizon model where a multi-product monopolist is endowed with a chance to develop a new product in each period. The quality of a newly developed product can be either high or low. The monopolist is assumed to have an established product whose quality is known to be high to consumers. After developing a new product, the firm decides whether or not to extend its high quality product brand name to the new product. Consumers believe that brand name matters; if the high quality product brand name is extended to a new product, they believe that the new product is also of high quality as long as all the previous products with the same brand name were of high quality. This type of belief concerning brand extension allows the producer of a new high quality product to signal its quality with less price distortion than is needed otherwise. Once the brand name is extended to a low quality product, consumers ignore any signaling value of brand extension and respond only to price signaling in the future. In the equilibrium with brand extension, the monopolist extends brand name only to high quality products. The incentive to cheat by extending brand name to a low quality product is prevented by the loss of brand capital (reputation) when it is misused.

The reputation mechanism used for brand extension in my model is very similar to the one in Klein and Leffler (1981) and Shapiro (1983). In both models, firms refrain from deceiving consumers because they do not wish to incur a long-term loss of reputation rents. The difference is that the Klein-Leffler-Shaprio model assumes a single

\footnotetext{
${ }^{1}$ An experience good is a product whose quality can be ascertained only after using it. Thus inspection
} 
product monopolist who chooses quality in each period. The decision is whether or not to shade the quality of the product in each period. Once quality is cut by the firm, its reputation is lost and so is its reputation rent. Thus, the reputation mechanism in the Klein-Leffler-Shapiro model is intra-product. My model, in contrast, considers a multiproduct firm for whom the quality of each product is exogenously given and unalterable. The decision for the firm is thus inter-product in that its decision is whether or not to extend the existing high quality brand name to a new product, associating the quality of the new product with the quality represented by the established brand name in the minds of consumers.

The simple model of brand extension developed in this paper is related to the model of Wernerfelt (1988) in that both use the firm's future profits as a bond. ${ }^{2}$ There is, however, a major difference between the two papers in that the source of future profits used as a bond is different. More precisely, Wernerfelt's model relies on future profits from the established product as a bonding mechanism, which requires that the quality of the old product should be unsettled in the minds of consumers for brand extension to be effective as a signal of new product quality. This implies that his theory is inapplicable to the case where the quality of the old product is firmly established, which seems to be the norm in most cases of brand extension. My model is immune from this problem because it uses future profits from future products as a bond; the reputation mechanism works through the option value of profitable future products that can be associated with the name brand when their qualities are high. Thus, my model is consistent with the observation that the value of brand capital includes not only the incremental value of a 
business above the value of its physical assets due to the market position achieved by its brand but also "the extension potential of the brand" (Tauber, 1988).

Bagwell (1991) also considers a signaling problem for a multi-product monopolist whose quality of products is initially unknown to consumers. Unlike this paper and Wernerfelt's (1988), he assumes that product qualities are uniform across products in the same product line due to the use of a common input of equal quality. Moreover, in his model, all products are introduced at the same time. Thus, the issue of brand extension does not arise. ${ }^{3}$

Finally, Tadelis (1996) provides an interesting model of reputation where intangible assets such as the name of a firm can have transferable value. In a model of adverse selection, he shows that names are traded in all equilibria, that is, reputation always has a positive value. He derives this result by assuming that transactions carried out in the market for names are unobservable. This assumption allows him to eliminate non-reputational equilibria often found in the standard game-theoretic models of reputation (Fudenberg and Tirole, 1991). Tadelis's model and my model can be considered complementary in that he focuses on inter-firm transfer of reputation whereas I focus on inter-product transfer of reputation within a firm.

The rest of the paper is organized in the following way. In section 2, I present a standard price signaling model of product quality in an isolated single market. Section 3

\footnotetext{
${ }^{2}$ Wernerfelt (1989) uses the term "umbrella branding" for brand extension.

${ }^{3}$ An interesting question to ask in Bagwell's model is whether it may be more profitable for the firm to sequentially introduce products. Since the products are assumed to share the same quality basis, it may be better to initially introduce only one product and establish reputation. Then the next product can be introduced at the complete information monopoly price without distortion. This idea is fully developed in Choi (1996) in the context of bundling where I endogenize the timing of product introductions and demonstrates that sequential product introduction can be profitable since it allows leveraging of reputation in one market to another.
} 
uses the basic model in section 2 as a building block for analyzing brand extension as informational leverage. I demonstrate how a multi-product monopolist can use brand extension to leverage information in one market to another. In section 4 , I analyze an explicit example with linear demand. Section 5 discusses the potential costs of brand extension, which can shed some light on when brand creation is used vis-a-vis brand extension. Section 6 contains concluding remarks.

\section{A Price Signaling Model of Product Quality in a Single Market}

In this section, I introduce a standard signaling model of an experience good where price is used as a signal of quality. The model in this section will be used as a building block in analyzing brand extension later. Without brand extension, a multi-product producer's signaling problem in each market can be considered independently of each other unless the quality of products is correlated. Thus, the equilibrium outcome characterized in this section will be replicated in each market if there is no brand extension and serves as a benchmark case. The particular model in this section is a variation of Milgrom and Roberts (1986) and Bagwell (1991). Thus, readers are referred to their papers for further details.

Consider a monopolistic firm that has just developed a new product. The quality of the product may be either high $(\mathrm{H})$ or low $(\mathrm{L})$. The firm knows the actual quality of the product, but potential consumers do not know it before purchase. In other words, the product has the characteristics of an "experience good" (Nelson, 1974). The a priori probability that the producer is endowed with the ability to produce the high (low) quality 
product is denoted by $\alpha(1-\alpha){ }^{4}$ Let $c_{H}$ and $c_{L}$ be the cost of production for the high quality and low quality producer, respectively, with $c_{H}>c_{L}$ reflecting the fact that high quality goods are more costly to produce.

I consider an infinite horizon model. The first period is the introductory phase in which the quality of the product is still unknown. There is no credible way to directly convey information regarding the product before consumers make their initial purchases. Consumers, however, may infer the quality of the product through the firm's price decision. $^{5}$ After the first period, consumers are assumed to know quality from previous experience or by reading quality reviews such as Consumer Reports. Thus, the mature phase starts from the second period during which the market operates under complete information.

More specifically, the game is played in the following sequence. In the first period, the monopolist chooses a price. Consumers observe the price, form beliefs as to the probability that the product quality is high, and make purchase decisions. Let $\rho(P)$ be the consumers' posterior belief that quality is high when the price is $P$. The demand function for the product which depends on the price and consumers' beliefs is denoted by $D(P, \rho)$, which is differentiable, decreasing in $P$, and increasing in $\rho$.

Let $\pi(P, q, \rho)$ be the profit function of the firm of true quality $q(q=H$ or $L)$ that sets a price $\mathbf{P}$ when consumers believe that the firm's quality is high with probability $\rho$ :

\footnotetext{
${ }^{4} \mathrm{I}$ assume that the prior probability of each quality is exogenously determined by nature. As formalized by Bagwell (1991) in the context of international trade, however, the prior can be endogenized as the choice of a monopolist with private information concerning the relative future profits of high and low quality products.

${ }^{5}$ Many authors have considered other means of signaling such as advertising (Milgrom and Roberts, 1986), warranties (Dybvig and Lutz, 1993), etc. I do not consider these other signaling instruments. However, the intuition of the paper will survive these extensions.
} 


$$
\pi(P, q, \rho)=\left(P-c_{q}\right) D(P, \rho), \text { where } q=H, L
$$

It is assumed that $\pi(P, q, \rho)$ is strictly concave in $P$. Then I can define $P(q, \rho)$ as the unique maximizer of $\pi(P, q, \rho)$, i.e.,

$$
\mathrm{P}(\mathrm{q}, \rho)=\underset{P}{\arg \max }\left(\mathrm{P}-\mathrm{c}_{\mathrm{q}}\right) \mathrm{D}(\mathrm{P}, \rho)
$$

Since consumers have complete information about the quality of the product from the second period on, it is useful to define the complete information monopoly prices for the high and low quality products, denoted by $\mathrm{P}_{\mathrm{H}}{ }^{*}$ and $\mathrm{P}_{\mathrm{L}}{ }^{*}$, respectively:

$$
\mathrm{P}_{\mathrm{H}}^{*}=\mathrm{P}(\mathrm{H}, 1) \text { and } \mathrm{P}_{\mathrm{L}}{ }^{*}=\mathrm{P}(\mathrm{L}, 0)
$$

Let $\pi_{\mathrm{H}}{ }^{*}$ and $\pi_{\mathrm{L}}{ }^{*}$ denote the corresponding complete information monopoly profits for high and low quality producers, respectively:

$$
\pi_{\mathrm{H}}^{*}=\pi\left(\mathrm{P}_{\mathrm{H}}{ }^{*}, \mathrm{H}, 1\right) \text { and } \pi_{\mathrm{L}}^{*}=\pi\left(\mathrm{P}_{\mathrm{L}}^{*}, \mathrm{~L}, 0\right)
$$

The following condition guarantees that for a high quality producer to signal its quality, its price needs to be distorted away from its complete information monopoly price $\mathbf{P}_{\mathrm{H}}{ }^{*}$.

$$
\pi\left(\mathrm{P}_{\mathrm{H}}^{*}, \mathrm{~L}, 1\right)>\pi_{\mathrm{L}}^{*}
$$

Condition (5) says that if the high quality firm charges the complete information monopoly price for the high quality product $\mathrm{P}_{\mathrm{H}}{ }^{*}$ and consumers believe that the product is of high quality after observing $P_{H}{ }^{*}$, the low quality firm has an incentive to mimic the high quality firm by charging $P_{H}{ }^{*}$ rather than revealing its identity by charging its own complete information monopoly price $\mathrm{P}_{\mathrm{L}}{ }^{*}$.

An alternative way to state condition (5) is by defining $\underline{P}$ and $\bar{P}$ as the roots satisfying the following relationship, with $\underline{P}<\mathrm{P}(\mathrm{L}, 1)<\bar{P}$ : 


$$
\pi(\mathrm{P}, \mathrm{L}, 1)=\pi_{\mathrm{L}}^{*}
$$

Then, in order for the high quality firm to reveal its quality, it is necessary that the price charged by the high quality firm should lie outside the segment of $(\underline{P}, \bar{P})$. Thus, condition (5) is equivalent to $\mathrm{P}_{\mathrm{H}}{ }^{*} \in(\underline{P}, \bar{P})$.

Now let $\hat{P}(\mathrm{H})$ and $\hat{P}(\mathrm{~L})$ be the prices charged by the high and low quality producers, respectively, and let $\hat{\rho}(\mathrm{P})$ be the consumers' posterior beliefs as to the probability that the product quality is high after observing price $P$. Then, the triplet $\{\hat{P}(\mathrm{H}), \hat{P}(\mathrm{~L}), \hat{\rho}(\mathrm{P})\}$ forms a Perfect Baysian Equilibrium (PBE) if and only if it satisfies the following sequential rationality $(\mathbf{P})$ and Bayesian consistency in beliefs (B).

$$
\hat{P}(\mathrm{q}) \in \underset{P}{\arg \max } \pi(\mathrm{P}, \mathrm{q}, \hat{\rho}(\mathrm{P}))=\underset{P}{\arg \max }\left(\mathrm{P}-\mathrm{c}_{\mathrm{q}}\right) \mathrm{D}(\mathrm{P}, \hat{\rho}(\mathrm{P}))
$$

(B) If $\hat{P}(\mathrm{H})=\hat{P}(\mathrm{~L})=\mathrm{P}$, then $\hat{\rho}(\mathrm{P})=\rho$

$$
\text { If } \hat{P}(\mathrm{H}) \neq \hat{P}(\mathrm{~L}) \text {, then } \hat{\rho}(\hat{P}(\mathrm{H}))=1 \text { and } \hat{\rho}(\hat{P}(\mathrm{~L}))=0
$$

Potentially, there are two types of equilibria. In a separating equilibrium, the consumers identify high and low quality firms since they charge different prices. In a pooling equilibrium, consumers cannot update their beliefs just by observing the price since they charge the same price. For separation of types to occur, the high quality firm cannot charge a price in the set $(\underline{P}, \bar{P})$. Otherwise, the low quality firm will have an incentive to mimic the price. This implies that under condition (5), the high quality firm needs to distort its price in a separating equilibrium. Given $\hat{P}(\mathrm{H}) \notin(\underline{P}, \bar{P})$, the best action for the low quality producer is to charge its complete information monopoly price 
$P_{L}{ }^{*}$. Thus, there is no price distortion for the low quality producer in a separating equilibrium.

As usual, due to the freedom in specifying off-the-equilibrium beliefs, there is a plethora of equilibria. Most of these equilibria, however, are based on arguably implausible consumer beliefs. Cho and Kreps (1986) propose the so-called "intuitive criterion (C-K)" to pare down such unreasonable equilibria.

(C-K) Fix a particular PBE. Let $\hat{\pi}^{*}(q)$ be the equilibrium profit to the monopolist of type $\mathrm{q}$ in this particular PBE, where $\mathrm{q}=\mathrm{H}, \mathrm{L}$. Consider some deviation by a player who charges an off the equilibrium price $\mathrm{P}$, where $\mathrm{P}$ is neither $\hat{P}(\mathrm{H})$ nor $\hat{P}(\mathrm{~L})$. Then,

$$
\begin{aligned}
& \hat{\rho}(\mathrm{P})=1 \text { if } \underset{\rho}{\operatorname{Max}} \pi(\mathrm{P}, \mathrm{L}, \rho)<\hat{\pi}^{*}(\mathrm{~L}) \text { and } \underset{\rho}{\operatorname{Max}} \pi(\mathrm{P}, \mathrm{H}, \rho)>\hat{\pi}^{*}(\mathrm{H}) \\
& \hat{\rho}(\mathrm{P})=0 \text { if } \underset{\rho}{\operatorname{Max}} \pi(\mathrm{P}, \mathrm{H}, \rho)<\hat{\pi}^{*}(\mathrm{H}) \text { and } \operatorname{Max}_{\rho} \pi(\mathrm{P}, \mathrm{L}, \rho)>\hat{\pi}^{*}(\mathrm{~L})
\end{aligned}
$$

The idea of the intuitive criterion can be explained as follows. Suppose that $\mathbf{P}$ is an offthe-equilibrium price, i.e., $\mathrm{P}$ is neither $\hat{P}(\mathrm{H})$ nor $\hat{P}(\mathrm{~L})$. When $\underset{\rho}{\operatorname{Max}} \pi(\mathrm{P}, \mathrm{q}, \rho)<\hat{\pi}^{*}(\mathrm{q})$, a strategy of charging P can be said to be "equilibrium-dominated" for type q in the sense that a type $q$ firm cannot improve upon its equilibrium payoff by charging $\mathrm{P}$ no matter what the consumers' beliefs are; it can achieve a higher payoff by adhering to the equilibrium price prescribed to it. Thus, consumers are assumed to believe that such a price is never chosen by a type $\mathrm{q}$ firm. I shall limit my attention to equilibria that survive the intuitive criterion. 
Applying the intuitive criterion allows the high quality firm to select the least costly separating equilibria. In a separating equilibrium, any price outside $(\underline{P}, \bar{P})$ is equilibrium-dominated by type $\mathrm{L}$. Thus, the high quality firm's problem is equivalent to:

$$
\operatorname{Max}_{P} \pi(\mathrm{P}, \mathrm{H}, 1) \text { subject to } \mathrm{P} \notin(\underline{P}, \bar{P})
$$

Since it is assumed that $\pi(\mathrm{P}, \mathrm{H}, 1)$ is concave and $\underline{P}<\mathrm{P}_{\mathrm{H}}{ }^{*}=\mathrm{P}(\mathrm{H}, 1)<\bar{P}$, the high quality firm's optimal price will be either $\underline{P}$ or $\bar{P}$. To see which will be the preferred separating price, observe that:

$$
\begin{aligned}
& \pi(\bar{P}, \mathrm{H}, 1)-\pi(\underline{P}, \mathrm{H}, 1)=\left[\pi(\bar{P}, \mathrm{H}, 1)-\pi_{\mathrm{L}}^{*}\right]-\left[\pi(\underline{P}, \mathrm{H}, 1)-\pi_{\mathrm{L}}^{*}\right] \\
& =[\pi(\bar{P}, \mathrm{H}, 1)-\pi(\bar{P}, \mathrm{~L}, 1)]-[\pi(\underline{P}, \mathrm{H}, 1)-\pi(\underline{P}, \mathrm{~L}, 1)] \\
& \quad \text { (by definition of } \underline{P} \text { and } \bar{P} \text {; see Eq. (6)) } \\
& =\left(\mathrm{c}_{\mathrm{H}^{-}} \mathrm{c}_{\mathrm{L}}\right)[\mathrm{D}(\underline{P}, 1)-\mathrm{D}(\bar{P}, 1)]>0
\end{aligned}
$$

Thus, we have $\hat{P}(\mathrm{H})=\bar{P}$ in a separating equilibrium. ${ }^{6}$

To prove the existence of an intuitive separating equilibrium, consider the following triplet $\{\hat{P}(\mathrm{H}), \hat{P}(\mathrm{~L}), \hat{\rho}(\mathrm{P})\}$ such that $\hat{P}(\mathrm{H})=\bar{P}, \hat{P}(\mathrm{~L})=\mathrm{P}_{\mathrm{L}}{ }^{*}, \hat{\rho}(\mathrm{P})=1$ if $\mathrm{P} \in[\underline{P}, \bar{P})$, and $\hat{\rho}(\mathrm{P})=0$ otherwise. Then, it is clear that the $\mathrm{L}$ type firm does not have any incentive to deviate from $P_{L}^{*}$.

For the type $\mathrm{H}$ firm, the only price to check as a possible deviation price is $\mathrm{P}(\mathrm{H}, 0)$. Then, we can find a $P^{\prime}(>\bar{P})$ such that

\footnotetext{
${ }^{6}$ In this model, the price is distorted upward to signal product quality. There are also models of introductory pricing where high quality must be signaled through a price that is lower than the full information price (Tirole, 1988). The direction of price distortion, however, is inconsequential for brand extension to be useful. As long as the introductory price needs to be distorted, upward or downward, to signal quality, brand extension can be used to reduce the distortion.
} 


$$
\pi\left(P^{\prime}, \mathrm{L}, 1\right)=\pi(\mathrm{P}(\mathrm{H}, 0), \mathrm{L}, 0)
$$

Note that (8) implies that $\mathrm{D}(\mathrm{P}(\mathrm{H}, 0), 0)>\mathrm{D}\left(P^{\prime}, 1\right)$ since $P^{\prime}>\vec{P}$.

Therefore, we have

$$
\begin{aligned}
& \pi(\bar{P}, \mathrm{H}, 1)-\pi(\mathrm{P}(\mathrm{H}, 0), \mathrm{H}, 0)>\pi\left(P^{\prime}, \mathrm{H}, 1\right)-\pi(\mathrm{P}(\mathrm{H}, 0), \mathrm{H}, 0) \\
& =\left[\pi\left(P^{\prime}, \mathrm{H}, 1\right)-\pi\left(P^{\prime}, \mathrm{L}, 1\right)\right]-[\pi(\mathrm{P}(\mathrm{H}, 0), \mathrm{H}, 0)-\pi(\mathrm{P}(\mathrm{H}, 0), \mathrm{L}, 0)] \text { (by Eq. (8)) } \\
& =\left(\mathrm{c}_{\mathrm{H}} \mathrm{c}_{\mathrm{L}}\right)\left[\mathrm{D}(\mathrm{P}(\mathrm{H}, 0), 0)-\mathrm{D}\left(P^{\prime}, 1\right)\right]>0
\end{aligned}
$$

This proves that the contemplated deviation to $\mathrm{P}(\mathrm{H}, 0)$ is not profitable for the $\mathrm{H}$ firm; the triplet described above forms an intuitive separating equilibrium.

In the Appendix, I also show that there is no pooling PBE that survives the intuitive criterion. The discussion above is summarized in the following Proposition. Proposition 1. There exists a unique Perfect Baysian Equilibrium that survives the ChoKreps intuitive criterion. It is characterized by $\hat{P}(\mathrm{H})=\bar{P}$ and $\hat{P}(\mathrm{~L})=\mathrm{P}_{\mathrm{L}}{ }^{*}$.

This characterization of the signaling outcome for a single product monopolist will serve as a benchmark case for the analysis of brand extension in the next section.

\section{Brand Extension as Informational Leverage}

In this section, I extend the analysis of the signaling problem facing a single product monopolist to a multi-product monopolist. I develop a model of brand extension in which a monopolistic producer of reputable quality extends its brand name to a new product. For this purpose, I consider a monopolist who already produces a product whose quality is established to be high. 
The model is a discrete time infinite horizon one in which the monopolist is endowed with an opportunity to introduce a new product with probability $\mu$ in each period. Given a chance to introduce a new product, the conditional probability that the monopolist will be endowed with the ability to produce a high quality product is given by $\alpha$. The quality realization for each product is assumed to be uncorrelated across products. $^{7}$ For simplicity, it is assumed that each potential product market is identical in that consumers have the same demand function and the cost of each new product is given by the same $c_{H}$ and $c_{L}$ for the high quality and low quality products, respectively, where $c_{H}>c_{L}$. In each period a new product is available, the monopolist has a choice of extending the brand name of the established product to the new one. I am interested in whether brand extension can be used as a signal of quality.

Consider the following type of equilibrium. Consumers believe that a new product is of high quality if the established brand is used for the new product as long as all the previcus products with the same brand name were of high quality. Once the brand name is extended to a low quality product, consumers ignore any signaling value of brand extension and respond only to price signaling in the future. The monopolist extends brand name only to high quality products. Thus, consumers' beliefs are confirmed. When brand extension is used, the monopolist charges price $\mathrm{P}^{\mathrm{BX}}$ in the introductory phase. Without brand extension, the price needed to signal high quality is $\bar{P}$ as in the previous section. Once consumers buy the product and the quality is ascertained to be high, the monopolist can charge the complete information monopoly price $\mathrm{P}_{\mathrm{H}}{ }^{*}$ in the mature phase.

\footnotetext{
${ }^{7}$ This assumption is in contrast to Bagwell (1992) who assumes perfect correlation of quality across products in the same product line. His assumption is more appropriate if the quality of final products is largely determined by the quality of inputs and the same input is used for all products.
} 
For these strategies to form an equilibrium, the low quality producer of a new product should not have the incentive to exercise brand extension and charge $\mathrm{P}^{\mathrm{BX}}$ in the introductory phase. Note that in this model, contrary to Wernerfelt (1986), brand extension has no consequences for the products already introduced since their qualities are already known to consumers. Let me define:

$$
\begin{aligned}
\mathrm{v}^{\mathrm{BX}} & =\pi\left(\mathrm{P}^{\mathrm{BX}}, \mathrm{H}, 1\right)+\frac{\delta}{1-\delta} \pi_{\mathrm{H}}{ }^{*} \\
\mathrm{v} & =\pi(\bar{P}, \mathrm{H}, 1)+\frac{\delta}{1-\delta} \pi_{\mathrm{H}}{ }^{*}
\end{aligned}
$$

Then, $\mathrm{v}^{\mathrm{BX}}$ is the value of having a high quality product when brand extension is used whereas $v$ is the corresponding value without brand extension. Let me define a $\widetilde{P} \in\left(\underline{P}, \mathrm{P}_{H^{*}}\right)$ such that

$$
\pi(\widetilde{P}, \mathrm{H}, 1)=\pi(\bar{P}, \mathrm{H}, 1)
$$

For brand extension to be a useful signaling device for the high quality producer, it is required that $\mathrm{P}^{\mathrm{BX}} \in(\widetilde{P}, \bar{P})$.

If the monopolist has a low quality product in a given period and refrains from brand extension, its expected profit is:

$$
\left[\pi_{\mathrm{L}}^{*}+\frac{\delta}{1-\delta} \pi_{\mathrm{L}}^{*}\right]+\frac{\delta}{1-\delta} \beta \mathrm{v}^{\mathrm{Bx}}, \text { where } \beta=\mu \alpha
$$

If it were to deviate and sell at the price of $\mathrm{P}^{\mathrm{BX}}$ with brand extension, its profit is:

$$
\left[\pi\left(\mathrm{P}^{\mathrm{Bx}}, \mathrm{L}, 1\right)+\frac{\delta}{1-\delta} \pi_{\mathrm{L}}^{*}\right]+\frac{\delta}{1-\delta} \beta \mathrm{v}
$$

By deviating, the firm can earn the short-term gain of $\pi\left(\mathrm{P}^{\mathrm{BX}}, \mathrm{L}, 1\right)-\pi_{\mathrm{L}}^{*}(>\pi(\bar{P}, \mathrm{~L}, 1)-$ $\pi_{\mathrm{L}}{ }^{*}=0$ ). However, it destroys future opportunities of brand extension. For deviation 
not to be profitable, the following incentive compatibility condition should hold:

$$
\pi\left(\mathrm{P}^{\mathrm{BX}}, \mathrm{L}, 1\right)-\pi_{\mathrm{L}}^{*} \leq \frac{\delta}{1-\delta} \beta\left(\mathrm{v}^{\mathrm{BX}}-\mathrm{v}\right)=\frac{\delta}{1-\delta} \beta\left[\pi\left(\mathrm{P}^{\mathrm{BX}}, \mathrm{H}, 1\right)-\pi(\bar{P}, \mathrm{H}, 1)\right]
$$

The left hand side of inequality (14), $\Gamma=\pi\left(\mathrm{P}^{\mathrm{Bx}}, \mathrm{L}, 1\right)-\pi_{\mathrm{L}}{ }^{*}$, is the short-term gain by the monopolist who extends its high quality brand name to a low quality product, milking reputation on its established product. The right hand side, $\Lambda=\frac{\delta}{1-\delta} \beta\left[\pi\left(\mathrm{P}^{\mathrm{BX}}, \mathrm{H}, 1\right)-\right.$ $\pi(\bar{P}, \mathrm{H}, 1)]$, is the value of brand capital (reputation) that is lost by deceiving consumers when the monopolist extends its brand name to a low quality product.

Let me define a set:

$$
\mathrm{B}=\left\{\mathrm{P} \mid \pi(\mathrm{P}, \mathrm{L}, 1)-\pi_{\mathrm{L}}{ }^{*} \leq \frac{\delta}{1-\delta} \beta[\pi(\mathrm{P}, \mathrm{H}, 1)-\pi(\bar{P}, \mathrm{H}, 1)]\right\} \cap(\widetilde{P}, \bar{P}) .
$$

If set $B$ is empty, brand extension cannot be of any help in the introduction of a new product. However, if B is nonempty, brand extension can help the high quality product be introduced with less price distortion for the monopolist. The type of equilibrium I consider has a "bootstrapping" nature. As in the reputation model of Klein-LefflerShapiro, brand extension matters only because consumers believe it matters. As a result, my model has a multiplicity of equilibria in that any price in set B can be sustained as an equilibrium price with brand extension.

A sufficient condition for the existence of set $B$ is

$$
\frac{\delta}{1-\delta} \beta>\frac{D(\bar{P}, 1)+\left(\bar{P}-c_{H}\right) \frac{\partial D(\bar{P}, 1)}{\partial P}}{D(\bar{P}, 1)+\left(\bar{P}-c_{L}\right) \frac{\partial D(\bar{P}, 1)}{\partial P}}(>1)
$$

To understand this condition, note that condition (14) is satisfied with equality at $\mathrm{P}=\bar{P}$; $\Gamma(\bar{P})=\Lambda(\bar{P})$. Condition (15) says that $\Lambda(\mathrm{P})$ is steeper than $\Gamma(\mathrm{P})$ evaluated at $\bar{P}$. Since both $\Lambda(\mathrm{P})$ and $\Gamma(\mathrm{P})$ are negatively sloped at $\mathrm{P}=\bar{P}$, B is non-empty if condition 
(15) holds. The parameter $\beta$ represents the frequency of future profit opportunities.

Therefore, it is easier for brand extension to serve as a signal of quality with higher $\beta$ and $\delta$ since the monopolist uses its reputational rents in the future as a bond for quality.

Since quality signaling in the absence of brand extension involves upward distortion in prices $\left(\hat{P}(\mathrm{H})=\bar{P}>\mathrm{P}_{\mathrm{H}}{ }^{*}\right)$, brand extension can be welfare-improving for both the monopolist and consumers. As standard in the literature, I shall focus on the brand extension equilibrium that is optimal for the monopolist. In fact, when $\mathrm{B} \subseteq\left[\mathrm{P}_{\mathrm{H}}{ }^{*}\right.$, $\bar{P}$ ), the best equilibrium for the monopolist is also the best equilibrium for consumers and it constitutes the unique (constrained) Pareto-optimal equilibrium.

If $[\mathrm{k} \pi(\mathrm{P}, \mathrm{H}, 1)-\pi(\mathrm{P}, \mathrm{L}, 1)]$ is a quasi-concave function of $\mathrm{P}$ for $\mathrm{P} \in(\widetilde{P}, \bar{P})$ and $\mathrm{k}$ $>1$, then B is a convex set. Moreover, condition (15) becomes a necessary and sufficient condition for the nonemptiness of $\mathrm{B}$. Then, a simple characterization of the best brand extension equilibrium for the monopolist is possible. Let me define $\mathrm{P}^{\mathrm{inf}}$ as the infimum of the prices that belong to set $\mathrm{B}$. Then, the best brand extension equilibrium price is given by $\mathrm{P}^{\mathrm{BX}}=\max \left[\mathrm{P}^{\text {inf }}, \mathrm{P}_{\mathrm{H}}^{*}\right]$. Since set $\mathrm{B}$ is (weakly) expanding and $\mathrm{P}^{\mathrm{inf}}$ is (weakly) decreasing in $\frac{\delta}{1-\delta} \beta$, the benefit of brand extension increases as the future opportunity to introduce high quality products $(\beta)$ increases and the firm becomes more patient (i.e. higher $\delta$ ).

Figure 1 shows the cases where brand extension allows the introduction of a new product with a smaller distortion in price. In Case $\mathrm{I}, \mathrm{P}_{\mathrm{H}}{ }^{*}<\mathrm{P}^{\text {inf }}$ and the best equilibrium price with brand extension is $P^{\mathrm{inf}}$. In case II, the incentive constraint (14) is not binding even at the full information monopoly price $\left(\mathrm{P}^{\text {inf }}<\mathrm{P}_{\mathrm{H}}{ }^{*}\right)$, i.e., $\mathrm{P}^{\mathrm{BX}}=\mathrm{P}_{\mathrm{H}}{ }^{*}$. 
Case I. $\mathrm{P}_{\mathrm{H}^{*}}<\mathrm{P}^{\mathrm{inf}}=\mathrm{P}^{\mathrm{BX}}$

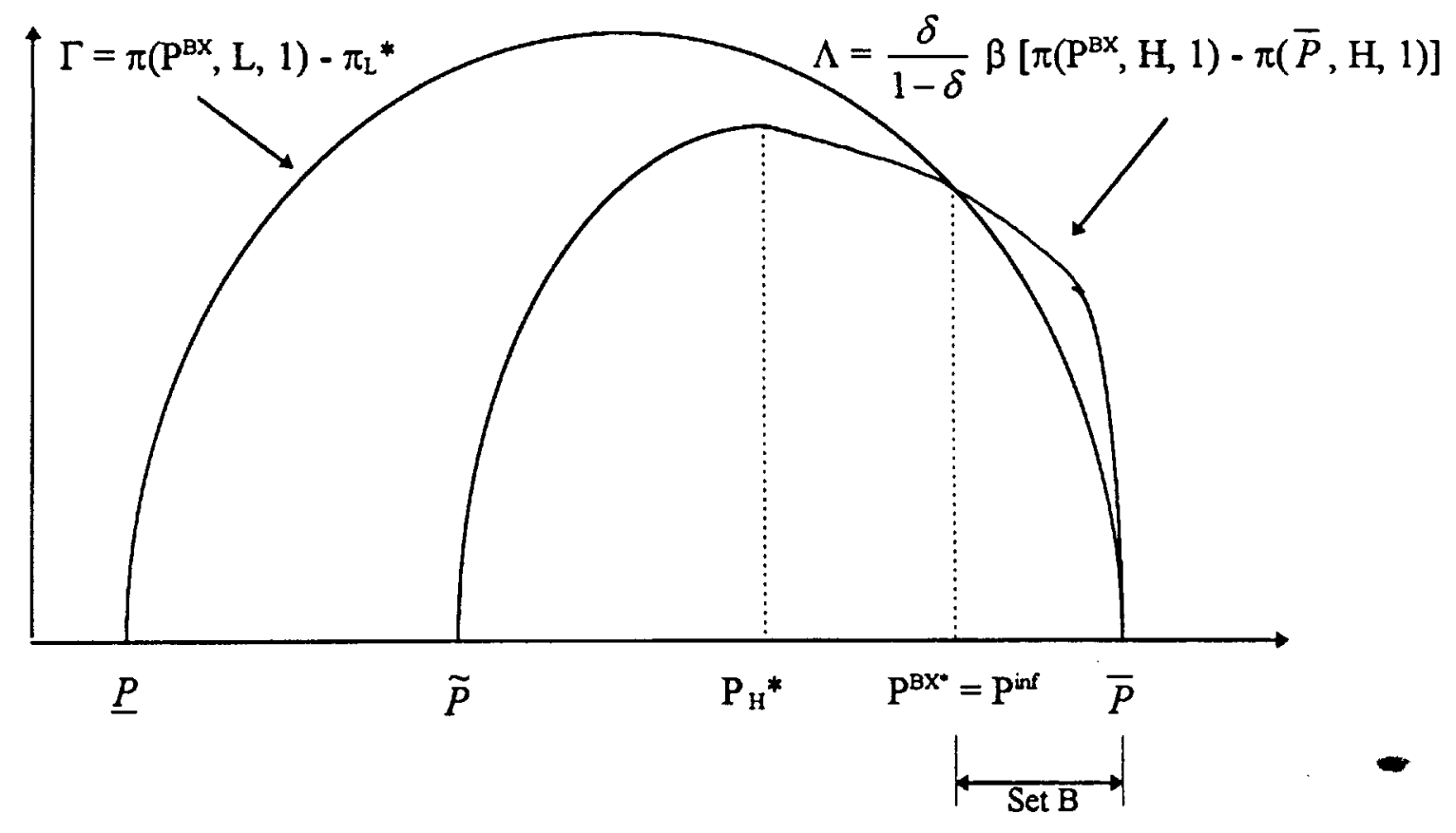

Case II. $\mathrm{P}^{\mathrm{inf}}<\mathrm{P}_{\mathrm{H}}{ }^{*}=\mathrm{P}^{\mathrm{BX}}$

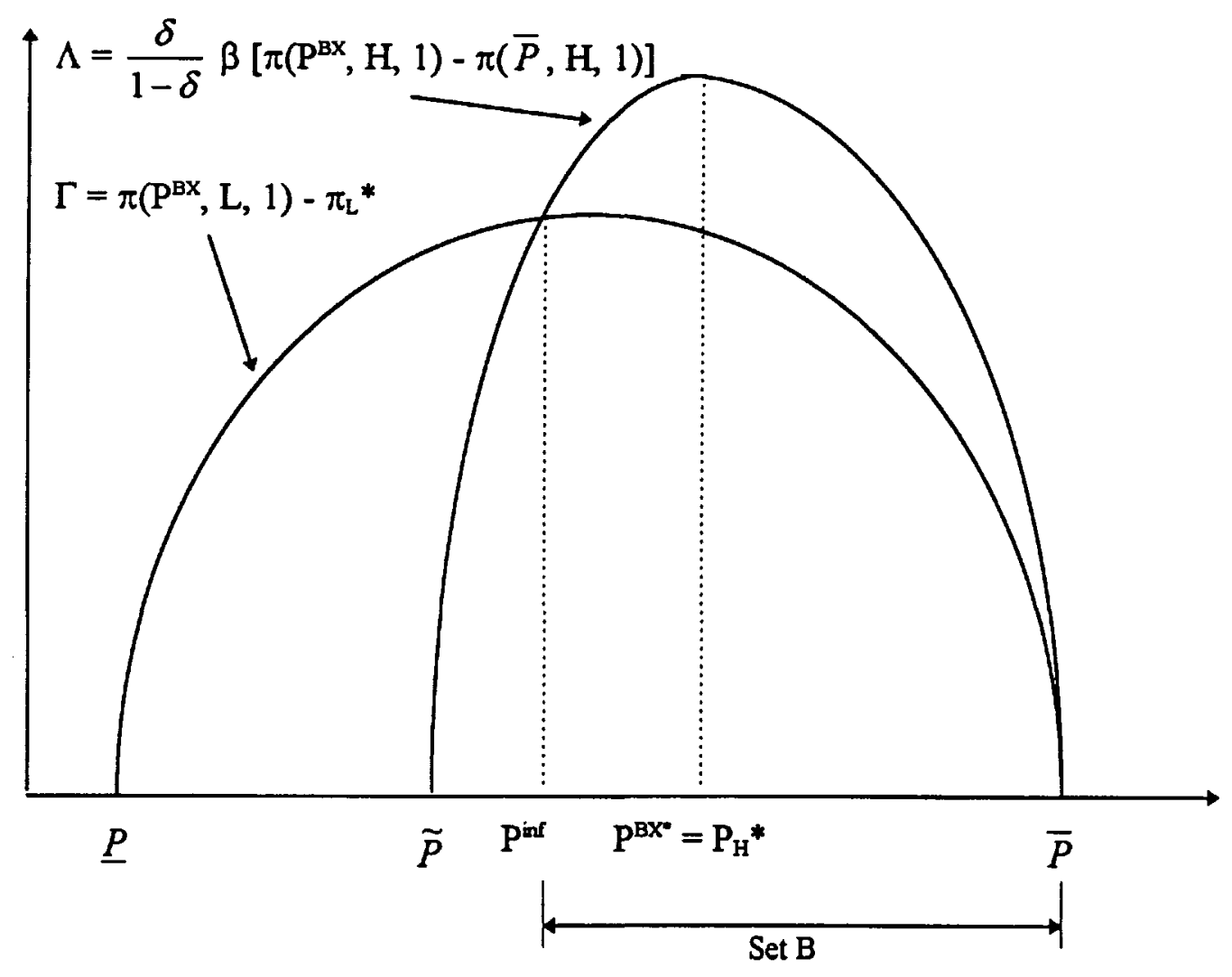

Figure 1. Brand Extension Equilibria 
Wernerfelt (1988) also provides a theory of brand extension in which extending an established brand name to a new product can signal that the new product is of high quality. In both models, the multi-product firm use its reputation as a bond for quality by using a brand name for an established product. However, there is a major difference in the way in which the bond is posted in the two models. Wernerfelt's model relies on future profits from the established product as a mechanism for posting a bond. This requires that consumers remain uncertain about the quality of the established product although they have already experienced it. Otherwise, there cannot be any harmful repercussions from extending a brand name to a low quality new product since brand extension does not involve any physical tie-ins and relies only on consumers' perception (for instance, if I like Coke Classic and I am sure about its quality, why should I refrain from consuming it just because I do not like Cherry Coke that shares the same brand Coke?). It is, therefore, necessary that the quality of the old product be unsettled in the minds of consumers for brand extension to be effective as a signal of new product quality. This implies that his theory is inapplicable to the case where the quality of the old product is firmly established. ${ }^{8}$ My model avoids this problem by assuming the existence of (uncertain) future opportunities for new product introductions. This allows the multi-product firm to use as a bond future profits from future products that can be associated with the same brand if their qualities turn out to be high. In this case, the reputation mechanism works through the option value of future brand extension opportunities. ${ }^{9}$

\footnotetext{
${ }^{8}$ According to Wernerfelt (1989, p.459), brand extension in his model is tantamount to "inviting consumers to pool their experience with the two products to infer the quality of both."

${ }^{9}$ As in this paper, DeGraba and Sullivan (1995) note the possibility that brand extension to a low quality product can impair the value of a brand name when used to introduce new products in the future, but do not elaborate on this.
} 


\section{Analysis of a Linear Demand Example}

In this section, I analyze an explicit example of linear demand as in Bagwell and Riordan (1991). There is a continuum of consumers with mass 1 , each with a potential demand of at most one. Consumers have a common reservation value for the low quality product, $\mathrm{r}<1$. Consumers, however, have different reservation values for the high quality product, which are distributed uniformly between $r$ and $r+1$. The assumption of uniform distribution implies that the demand for the high quality product is linear, i.e., $\mathrm{D}(\mathrm{P}, 1)=$ $(1+r)-P$. Let us normalize the production cost so that $c_{L}=0$ and $c_{H}=c(<r+1)$. It is straightforward to verify that the complete information monopoly price and profits for the high quality producer are given by:

$$
\mathrm{P}_{\mathrm{H}}{ }^{*}=\frac{1+r+c}{2} \text { and } \pi_{\mathrm{H}}^{*}=\left(\frac{1+r-c}{2}\right)^{2}
$$

For the low quality producer, $\mathrm{P}_{\mathrm{L}}{ }^{*}=\mathrm{r}$ and $\pi_{\mathrm{L}}{ }^{*}=\mathrm{r}$. When it mimics the high quality producer's price and successfully convinces consumers that it is a high quality producer, its profit is $\pi(\mathrm{P}, \mathrm{L}, 1)=\mathrm{P}(1+\mathrm{r}-\mathrm{P})$. This implies that $\bar{P}=1$. Thus, the condition that price distortion is necessary for signaling is:

$$
\mathrm{r}+\mathrm{c}<1
$$

When condition (5)' holds, the high quality producer's profit in a signaling equilibrium is given by

$$
\hat{\pi}^{*}(\mathrm{H})=\pi(\bar{P}, \mathrm{H}, 1)=\mathrm{r}(1-\mathrm{c})
$$

Now let us consider the possibility of brand extension. In this linear example,

$$
\Gamma=\pi\left(\mathrm{P}^{\mathrm{BX}}, \mathrm{L}, 1\right)-\pi_{\mathrm{L}}^{*}=\mathrm{P}(1+\mathrm{r}-\mathrm{P})-\mathrm{r}
$$




$$
\Lambda=\frac{\delta}{1-\delta} \beta\left[\pi\left(\mathrm{P}^{\mathrm{Bx}}, \mathrm{H}, 1\right)-\pi(\bar{P}, \mathrm{H}, 1)\right]=\frac{\delta}{1-\delta} \beta[(\mathrm{P}-\mathrm{c})((1+\mathrm{r}-\mathrm{P})-\mathrm{r}(1-\mathrm{c})]
$$

For this example, it can be verified that $[k \pi(P, H, 1)-\pi(P, L, 1)]$ is a quasi-concave function of $\mathrm{P}$ for $\mathrm{P} \in(\widetilde{P}, \bar{P})$ and $\mathrm{k}>1$. Thus, $\mathrm{B}$ is a convex set. The necessary and sufficient condition for the nonemptiness of $\mathrm{B}$ is $\mathrm{k}>\frac{1-r}{1-r-c}(>1)$, where $\mathrm{k}=\frac{\delta}{1-\delta} \beta$.

Moreover, $\mathrm{P}^{\mathrm{inf}}=\mathrm{r}+\frac{k}{k-1} \mathrm{c}$, which is strictly decreasing in $\mathrm{k}$. If $\mathrm{k} \geq \frac{1-r+c}{1-r-c}, \mathrm{P}^{\mathrm{inf}} \leq \mathrm{P}_{\mathrm{H}^{*}}$.

Thus, we have

$$
\begin{aligned}
\mathrm{P}^{\mathrm{BX}}=\max \left[\mathrm{P}^{\mathrm{inf}}, \mathrm{P}_{\mathrm{H}}^{*}\right] & =\mathrm{P}^{\mathrm{inf}}=\mathrm{r}+\frac{k}{k-1} \mathrm{c}, \text { if } \mathrm{k} \in\left(\frac{1-r}{1-r-c}, \frac{1-r+c}{1-r-c}\right) \\
& =\mathrm{P}_{\mathrm{H}}^{*}=\frac{1+r+c}{2}, \text { if } \mathrm{k} \geq \frac{1-r+c}{1-r-c}
\end{aligned}
$$

Figure 2 summarizes the brand extension equilibrium for this example. If $\mathrm{k}<$ $\frac{1-r}{1-r-c}$, the option value of future brand extension is not sufficiently important to prevent short-run opportunistic behavior. Thus, brand extension cannot be used for signaling purposes. If $k \in\left(\frac{1-r}{1-r-c}, \frac{1-r+c}{1-r-c}\right)$, future branding opportunities are sufficient to make brand extension an additional instrument of signaling. As $\mathrm{k}$ increases, the price distortion is reduced further to make the introductory price approach the full information price. If $\mathbf{k}$ is greater than $\frac{1-r+c}{1-r-c}$, the stake of maintaining reputation is high enough to make the incentive constraint no longer binding. This allows the firm to charge the full information price with brand extension. 


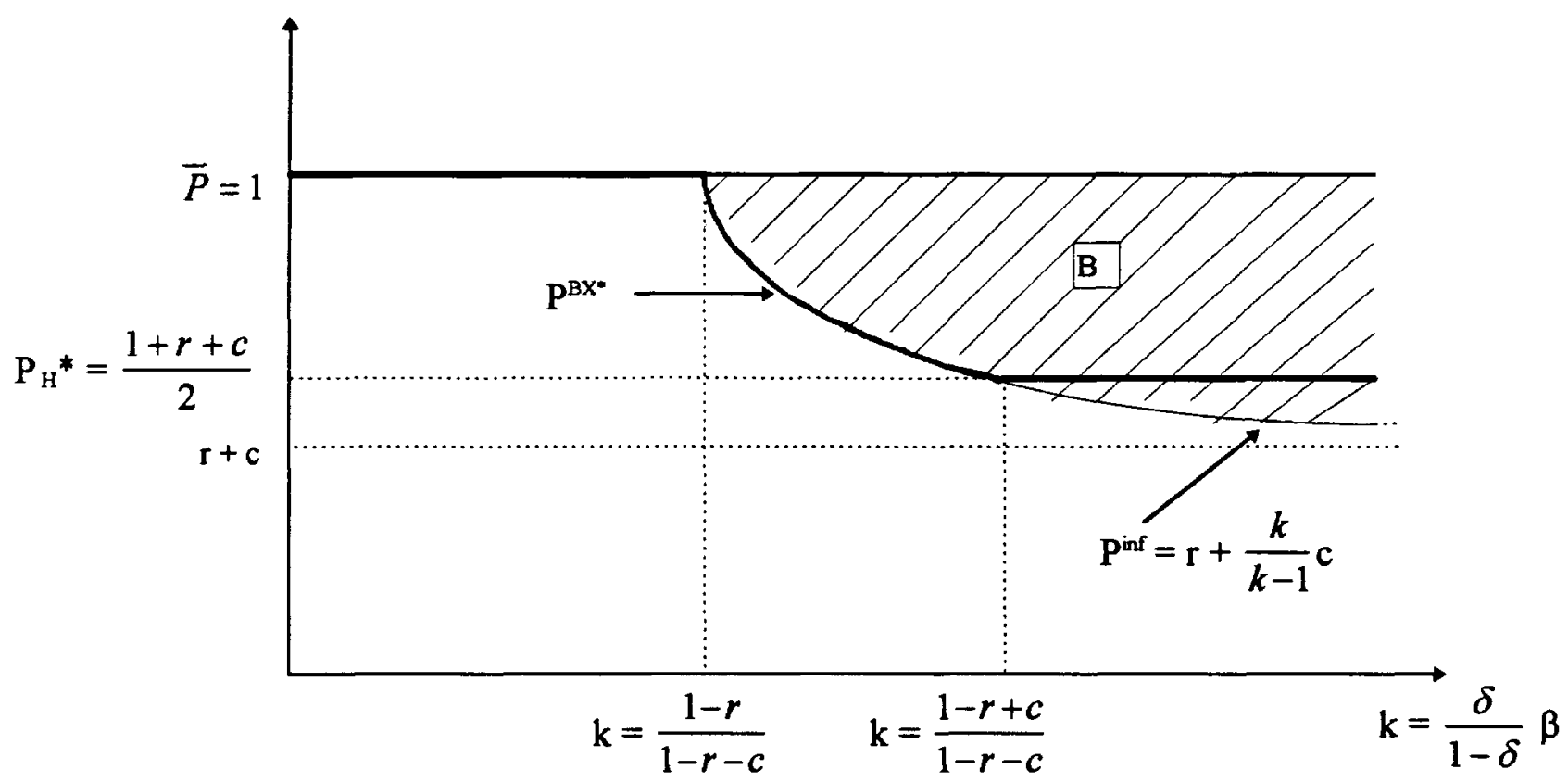

Figure 2. Brand Extension Equilibrium with Linear Demand

\section{Brand Extension vs. Brand Creation}

Up to now I have focused on the benefits of brand extension. I showed that brand extension allows a multi-product firm to introduce a new experience good with less price distortion by staking its reputation as a bond. The marketing literature, however, also points out potential costs of brand extension. Kimrey (1974), for instance, argues that an existing brand name identifies the product's location in horizontal attribute space. Thus, consumers are confused if it is used on different products and the meaning of the name is diluted. ${ }^{10}$ The consideration of this type of costs can shed some light on a firm's decision on when to use brand extension and when to create a new brand name. ${ }^{11}$ For instance, when Toyota company introduced its new line of luxury cars into the US, they created a new brand name of Lexus rather than extending its existing brand name. The same is true

\footnotetext{
${ }^{10}$ See also Sappington and Wernerfelt (1985).
} 
for the Infiniti division by Nissan for its own newly created line of luxury cars.

To address the relative merits of brand extension and creation, let me relax the assumption that every new product is identical in terms of production costs and demands. This heterogeneity is captured by indexing variables corresponding to each product by $i$. When the costs of brand extension are considered, the attractiveness of brand extension vis-à-vis brand creation hinges on cost-benefit analysis. As in Wernerfelt (1988), without being explicit about the source of costs, let me assume that the cost of brand extension is given by $\chi$, which is the same for every product. Suppose that brand extension allows the monopolist to introduce a new high quality product at $\mathrm{P}_{\mathrm{i}}^{\mathrm{Bx}}{ }^{\mathrm{Bx}}$ instead of at $\bar{P}_{\mathrm{i}}$. Then, the benefit of brand extension when introducing product $i$ is given by $\gamma_{i}=\left[\pi_{i}\left(P_{i}^{B X^{*}}, H, 1\right)\right.$ $\left.\pi_{\mathrm{i}}\left(\bar{P}_{\mathrm{i}}, \mathrm{H}, 1\right)\right]$. A brand name will be extended to a new product only when $\gamma_{\mathrm{i}} \geq \chi$. In general, $\gamma_{\mathrm{i}}$ depends on how much the price needs to be distorted from its complete information monopoly price to signal its quality, which in turn depends on the cost differential between the high and low quality products, $\left(c_{H}-c_{L}\right)$. As an extreme example, if $\left(c_{H}-c_{L}\right)$ is sufficiently large, i.e., if the high quality product is very expensive to produce compared to the low quality product and is aimed at a very limited market, condition (4) is violated contrary to the maintained assumption up to now. In this case, the low quality, low cost, mass market producer may be reluctant to target a limited market at the expense of the mass market even though it can sell at a higher price by mimicking the high quality producer. Then, the complete information price differential between the high and low quality producers is sufficiently large to make it unprofitable for the low quality producer to mimic the high quality producer. Thus, there is no cost

\footnotetext{
"I thank Editor P. Bolton for encouraging me to pursue this issue.
} 
associated with signaling even when the quality of the product is not initially known. In this extreme case, how small the cost of brand extension may be, a new brand will be created. It is not surprising that new brand names are created for high cost premium products whose market is limited to upscale consumers.

To analyze the relationship between the production cost differential and the benefit of brand extension more systematically, let me return to the linear demand case considered in Section 4. For simplicity, each product has the same demand function, but the cost of the high quality product is randomly drawn from a differential distribution function $\mathrm{F}$ with support $[0,1-r]$.

Then, it can be easily verified that for any two products $i$ and $j$, for which $c_{i}>c_{j}, \gamma_{i}$ $<\gamma_{\mathrm{j}}$; the benefit of brand extension is decreasing in the cost of the high quality product. Therefore, I can find a critical value of $c^{*}$ such that a brand name will be extended to a new product $i$ if and only if $c_{i}<c^{*} .{ }^{12}$ Thus, if $c_{i}$ is sufficiently high, a new brand name will be created for product $i$ since the costs of brand extension $\chi$ do not justify the benefits thereof. The complete information monopoly price is increasing in the production cost (see Tirole, 1988). This implies that when the production cost of the high quality product is high it will be targeted only to upscale consumers. Then, the firm can signal its quality with a relatively small distortion in prices even without brand extension since the low

\footnotetext{
${ }^{12}$ In the brand extension equilibrium with heterogenous production costs, the critical value $c^{*}$ is determined in the following way. First define $P^{\text {inf }}(\Lambda)$ as the infimum of the prices that satisfy $\pi(P, L, 1)$ $\pi_{\mathrm{L}}^{*} \leq \Lambda$. Note that $P^{\text {inf }}(\Lambda)$ is decreasing in $\Lambda$. To take account of the fact that the high quality producer's profit depends on its production cost, I will write its profit $\pi(P, H, \rho)$ as $\pi\left(P, c_{i}, \rho\right)$. Its complete information monopoly price is denoted by $P_{H^{*}}\left(c_{i}\right)$. Let $P^{B X}(c ; \Lambda)=\max \left[P^{\text {inf }}(\Lambda), P_{H^{*}}(c)\right]$ and $\gamma(c ; \Lambda)=$ $\pi\left(\mathrm{P}_{\mathrm{i}}{ }^{\mathrm{BX}}(\Lambda), \mathrm{c}, 1\right)-\pi(\vec{P}, \mathrm{c}, 1)$. Then, the brand extension equilibrium is characterized by the triplet $\left\{\mathrm{c}^{*}\right.$,
} 
quality, low cost, mass market producer may be reluctant to target a limited market at the expense of the mass market. Thus, my model generates a prediction which is consistent with the evidence that new brand names are created for high cost premium products such as Lexus, whose market is limited to upscale consumers.

\section{Conclusion}

This paper develops a theory of brand extension as a mechanism for informational leverage in which a firm leverages off a good's reputation in one market to alleviate the problem of informational asymmetry encountered in other markets. I show that brand extension helps a multi-product monopolist introduce a new experience good with less price distortion. The marketing literature refers to the concept of brand capital and provides empirical evidence that firms with a large stock of well-established brands have an advantage in introducing new products. The mechanism through which brand extension operates, however, has not been rigorously modeled. Wernerfelt (1988) is a notable exception. In his model, brand extension is an invitation to pool experience with two products. Thus, extension of brand name to a low quality product can have adverse effects on the parent product. For this to occur, it is crucial that the quality of the parent product be unsettled in the minds of consumers. This seems to be at odds with most cases of brand extension where the quality of parent products are firmly established. My model corrects this deficiency by relying on a different bonding mechanism where the potential loss of future brand extension opportunities is used as a guarantee of quality.

\footnotetext{
$\left.\Lambda^{*}, \mathrm{P}^{\mathrm{BX}}\right\}$ such that $\gamma\left(\mathrm{c}^{*} ; \Lambda^{*}\right)=\chi, \mathrm{P}^{\mathrm{BX}}\left(\mathrm{c}_{\mathfrak{i}}\right)=\max \left[\mathrm{P}^{\inf }\left(\Lambda^{*}\right), \mathrm{P}_{\mathrm{H}^{*}}\left(\mathrm{c}_{\mathrm{i}}\right)\right]$, and $\Lambda^{*}=$ $\frac{1-\delta}{\delta} \beta \int_{0}^{\infty} \gamma\left(c_{i} ; \Lambda^{*}\right) d F$.
} 
In this paper, I used brand extension to demonstrate the possibility of informational leverage. The logic of the theory, however, indicates that any marketing arrangement that purposely associates one product with another may serve the same purpose as brand extension, if the association of a high quality product with a low quality product can adversely affect the profits in the high quality product market. Therefore, any such arrangement may be considered a form of informational leverage. Elsewhere in Choi (1996), I prove this point by applying the theory of informational leverage to tying arrangements. As with brand extension, bundling a product of unknown quality with an already proven high quality one serves as a mechanism for posting a bond; it is a costly commitment for a low quality producer because he has to continue incurring the production cost of the low quality item which consumers refuse to purchase once its quality is revealed. Thus, the purpose of bundling is to reduce the cost of information. ${ }^{13}$ I also show that this possibility of informational leverage has important implications for the endogenous sequencing of product introductions. The most surprising result is that the sequential introduction of new products allows the use of informational leverage and thus creates the possibility that both products will be introduced even when neither of them is viable on its own. ${ }^{14}$

There are many extensions worth pursuing to test the robustness of the model. One obvious extension would be to allow for heterogeneity in consumers' information regarding the quality of products. Even though I am optimistic about the robustness of the basic insight of this paper, a detailed study awaits further research.

\footnotetext{
${ }^{13}$ For a theory of bundling as the leverage of "market power," see Whinston (1991) and Choi (1996).

${ }^{14} \mathrm{I}$ also discuss the welfare implications of bundling. When at least one of the products is not viable on its own, bundling is efficiency enhancing because it creates an otherwise nonexistent market. However, when both products are viable on their own, sequencing impairs welfare. The reason for welfare reduction
} 


\section{References}

Aaker, David A., "Brand Extension: The Good, the Bad, and the Ugly," Sloan Management Review, 1990 (31), pp. 47-56.

Bagwell, Kyle, "Optimal Export Policy for a New Product Monopoly," American Economic Review, December 1991, 81 (5), pp. 1156-1169.

Bagwell, Kyle, "Pricing to Signal Product Line Quality," Journal of Economics and Management Strategy, Spring 1992, 1(1), pp. 151-174.

Bagwell, Kyle and Riordan, Michael H., "High and Declining Prices Signal Product Quality," American Economic Review, March 1991, 81 (1), pp. 224-252.

Carbajo, Jose, De Meza, David and Seidman, Daniel J., "A Strategic Motivation for Commodity Bundling," Journal of Industrial Economics, March 1990, 38, pp. 283-298.

Cho, In-Koo and Kreps, David M., "Signaling Games and Stable Equilibria," Quarterly Journal of Economics, 1987 (102), 179-222.

Choi, Jay Pil, "Preemptive R\&D, Rent Dissipation and the 'Leverage Theory'," Quarterly Journal of Economics, 1996, pp. 1153-1181.

Choi, Jay Pil, "Informational Leverage and the Endogenous Timing of Product Introductions," mimeo., 1996.

DeGraba, Patrick and Sullivan, Mary W. "Spillover Effects, Cost Savings, R\&D and the Use of Brand Extensions," International Journal of Industrial Organization, 1995, pp. 229-248.

Dybvig, Philip. H. and Lutz, Nancy, 1993, "Warranties, Durability, and Maintenance: Two-Sided Moral Hazard in a Continuous-Time Model," Review of Economic Studies, 60, 575-597.

Fudenberg, Drew and Tirole, Jean, Game Theory, MIT Press, 1991.

Klein, Benjamin and Leffler, Keith B., "The Role of Market Forces in Assuring Contractual Performance," Journal of Political Economy, 1981 (89), 615-641.

Milgrom, Paul and Roberts, John, "Price and Advertising Signals of Product Quality," Journal of Political Economy, 1986 (94), 796-821.

is different from the usual leverage theory where bundling is used to extend monopoly power in one market to the other. Rather in this paper, it comes rather from a delay in product availability. 
Nelson, Phillip, "Information and Consumer Behavior," Journal of Political Economy, 1970 (78), 311-329.

Nelson, Phillip, “Advertising as Information," Journal of Political Economy, 1974 (81), 729-754.

Peckman, J. The Wheel of Marketing, Northbrook, Illinos: Nielsen, 1971.

Ries, Al and Jack Trout (1981) Positioning: The Battle for Your Mind New York: McGraw Hill.

Sappington, D. and Wernerfelt, B. "To Brand or Not to Brand? A Theoretical and Empirical Question," Journal of Business, 1985 (58), pp. 279-294.

Schmalensee, Richard, "A Model of Advertising and Product Quality," Journal of Political Economy, 1978 (86), 485-503.

Shapiro, Carl, "Premiums for High Quality Products as Rents to Reputation," Quarterly Journal of Economics, 1983 (98), pp. 659-680.

Tadelis, Steven, "What's in a Name?: Reputation as a Tradeable Asset," mimeo. 1996.

Tauber, Edward M. (1988) Brand Leverage: Strategy for Growth in a Cost-Control World, Journal of Advertising Research, 26-30.

Tirole, Jean, The Theory of Industrial Organization, Cambridge, MA: The MIT Press, 1988.

Tirole, Jean, "A Theory of Collective Reputations (with Applications to the Persistence of Corruption and to Firm Quality)," Review of Economic Studies, 1996 (63), 1-12.

Wernerfelt, Birger, "Umbrella Branding as a Signal of New Product Quality: An Example of Signaling by Posting a Bond," Rand Journal of Economics, Autumn 1988 (19), pp. 458-466.

Whinston, Michael D., "Tying, Foreclosure, and Exclusion," American Economic Review, 1991 (80), pp. 837-859. 


\section{Appendix: The Nonexistence of Intuitive Pooling Equilibrium}

Suppose that there exists a pooling equilibrium where $\hat{P}(\mathrm{H})=\hat{P}(\mathrm{~L})=\hat{P}$. Then, we can find a $P^{*}(>\max [\hat{P}, \mathrm{P}(\mathrm{L}, 1)])$ such that

$$
\pi\left(P^{*}, \mathrm{~L}, 1\right)=\pi(\hat{P}, \mathrm{~L}, \rho)
$$

Note that (A1) implies that $\mathrm{D}(\hat{P}, \rho)>\mathrm{D}\left(P^{*}, 1\right)$ since $P^{*}>\hat{P}$.

Thus we have

$$
\begin{aligned}
& \pi\left(P^{*}, \mathrm{H}, 1\right)-\pi(\hat{P}, \mathrm{H}, \rho) \\
& =\left[\pi\left(P^{*}, \mathrm{H}, 1\right)-\pi\left(P^{*}, \mathrm{~L}, 1\right)\right]-[\pi(\hat{P}, \mathrm{H}, \rho)-\pi(\hat{P}, \mathrm{~L}, \rho)] \text { (by Eq. (A1)) } \\
& =\left(\mathrm{c}_{\mathrm{H}}-\mathrm{c}_{\mathrm{L}}\right)\left[\mathrm{D}\left(P^{*}, 1\right)-\mathrm{D}(\hat{P}, \rho)\right]>0
\end{aligned}
$$

Note that charging $\left(P^{*}+\varepsilon\right)$ is equilibrium dominated for type $L$ but not type $\mathrm{H}$ for sufficiently small positive $\varepsilon$. As a result, type $H$ firms can convince consumers that their quality is high by charging $\left(P^{*}+\varepsilon\right)$. With this belief, inequality (A2) informs us that the deviation from $\hat{P}$ to $\left(P^{\#}+\varepsilon\right)$ increases type H's payoff. This completes the proof that there cannot be any intuitive pooling equilibrium. 


\title{
1996-1997 Discussion Paper Series
}

\author{
Department of Economics \\ Columbia University \\ 1022 International Affairs Bldg. \\ 420 West 118th Street \\ New York, N.Y., 10027
}

The following papers are published in the 1996-97 Columbia University Discussion Paper series which runs from early November to October 31 of the following year (Academic Year).

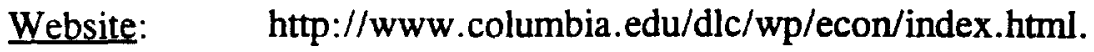

You may download any papers found on this site.

For Ordering Hardcopies:

Domestic orders for discussion papers are available for purchase at the cost of $\$ 8.00$ (U.S.) Per paper and $\$ 140.00$ (US) for the series.

Foreign orders cost $\$ 10.00$ (US) per paper and $\$ 185.00$ for the series.

To order discussion papers, please write to the Discussion Paper Coordinator at the above address along with a check for the appropriate amount, made payable to Department of Economics, Columbia University. Please be sure to include the series number of the requested paper when you place an order. 
1996-97 Discussion Papers

Economics Department, Columbia University

\begin{tabular}{|c|c|c|}
\hline $9697-01$ & Fertility Behavior Under Income Uncertainty & Ranjan, P. \\
\hline 9697-02 & Trade Restrictions, imperfect Competition and National Welfare with Foreign Capital Inflows & Ranjan, $\mathrm{P}$. \\
\hline 9697-03 & Restructuring an Industry during Transition: a Two-Priced Model & Ericson, $\mathrm{R}$. \\
\hline 9697-04 & A Conformity Test for Cointegration & Dhrymes, $\mathrm{P}$. \\
\hline $9697-05$ & $\begin{array}{l}\text { Low-Wage Employment Subsidies in a Labor-Turnover Model of the 'Natural Rate' (November } \\
\text { 1996) }\end{array}$ & $\begin{array}{l}\text { Hoon, H.T. } \\
\text { Phelps, E. }\end{array}$ \\
\hline 9697-06 & The Knowledge Revolution & Chichilnisky, G. \\
\hline 9697-07 & The Role of Absolute Continuity in "Merging Opinions" and "Rational Learning" & $\begin{array}{l}\text { Miller. R. } \\
\text { Sanchirico, C.W. }\end{array}$ \\
\hline 9697-08 & The Soviet Bloc and the Soviet Union: Why did they fall apart? & Desai, $\mathrm{P}$. \\
\hline $9697-09$ & Regionalism and Multilateral Tariff Cooperation & $\begin{array}{l}\text { Bagwell, } \mathrm{K} \text {. } \\
\text { Staiger, R. }\end{array}$ \\
\hline $9697-10$ & Supplier Relations and the Market Context: A theory of handshakes & McLaren, J. \\
\hline $9697-11$ & Vertical Foreclosure with the Choice of Input Specifications & $\begin{array}{l}\text { Choi, J.P. } \\
\text { Yi, S. }\end{array}$ \\
\hline 9697-12 & Equilibrium Vertical Foreclosure with Investment & $\begin{array}{l}\text { Choi, J.P. } \\
\text { Yi, S. }\end{array}$ \\
\hline $9697-13$ & Going Global: Transition from Plan to Market in the World Economy & Desai, $\mathbf{P .}$ \\
\hline $9697-14$ & Reciprocity, Non-discrimination and Preferential Agreements in the Multilateral Trading System & $\begin{array}{l}\text { Bagwell, K. } \\
\text { Staiger, R. }\end{array}$ \\
\hline $9697-15$ & Russia's Transition Toward the World Economy: Is the Market Mechanism Working? & Desai, $\mathrm{P}$. \\
\hline $9697-16$ & A Dynamic Analysis of Licensing: The "Boomerang" Effect and Grant-Back Clauses & Choi, J.P. \\
\hline
\end{tabular}


1996-97 Discussion Papers

Economics Department, Columbia University

\begin{tabular}{|c|c|c|}
\hline $9697-17$ & An Economic Theory of GATT & $\begin{array}{l}\text { Bagwell, K. } \\
\text { Staiger R.W. }\end{array}$ \\
\hline $9697-18$ & Climate Consumption and Climate Pricing from 1940 to 1990 & $\begin{array}{l}\text { Cragg, M.I. } \\
\text { Kahn, M.E. }\end{array}$ \\
\hline 9697-19 & Coddling Fatalistic Criminals: A Dynamic Stochastic Analysis of Criminal Decision-Making & O'Flaherty, B. \\
\hline $9697-20$ & Identification and Estimation of Structural VAR and MARMA Models & Dhrymes, $\mathrm{P}$. \\
\hline 9697-21 & Information, the Dual Economy, and Development & $\begin{array}{l}\text { Banarjee, A.V. } \\
\text { Newman, A.F. }\end{array}$ \\
\hline $9697-22$ & Matching in Perfect and Imperfect Worlds & $\begin{array}{l}\text { Legros, P. } \\
\text { Newman, A.F. }\end{array}$ \\
\hline $9697-23$ & The Labor Market and Corporate Structure & $\begin{array}{l}\text { Newman, A.F. } \\
\text { Acemoglu, D. }\end{array}$ \\
\hline $9697-24$ & National Herding and the Spatial Clustering of Bank Branches: An Empirical Analysis & $\begin{array}{l}\text { Chang, A. } \\
\text { Chaudhuri, S. } \\
\text { Jayaratne, J. }\end{array}$ \\
\hline $9697-25$ & Almost Everybody Disagrees Almost All the Time: The Genericity of Weakly-Merging Nowhere & $\begin{array}{l}\text { Miller, R.I. } \\
\text { Sanchirico, C.W. }\end{array}$ \\
\hline $9697-26$ & Brand Extension as Informational Leverage & Choi, J.P. \\
\hline
\end{tabular}

